\title{
Shared Responsibility for Population Health: A Personal Reflection
}

\author{
Tariq Bhatti, PhD
}

Much has been written, much has been talked about and much has been done to improve health, promote healthy development and enhance the quality of life. Efforts have focussed on individuals, on groups, on communities, on nations and global society. Physical, mental, social, economic, ecological and political models have been developed. Efforts have been made to understand the interactions and to integrate the various perspectives.

Despite these often heroic and pioneering efforts, the search goes on, questions are asked, answers are given, and more questions are raised. The quest continues. The curious revel in it, pragmatists are frustrated and others just observe and wait for it all to unfold someday - perhaps in a year, perhaps in a decade, or perhaps even later. Some give up, considering the search to be futile, others put up with the inevitable, while a few soldier on to find the ultimate answer, the truth, the reality, the secret to health, happiness and prosperity for all. Sometimes they find evidence, have an insight or an experience in their journey, and feel they have the answer, only to discover that there is more. So the journey of human development continues. New concepts and ideas arrive to renew, complement, or replace what has been there before. Such is the case with Population Health, introduced officially in 1994 - a new approach to help people improve their health.

Director, Population Health Development Division, Population Health Directorate, Room C865, Jeanne Mance Building, Ottawa, ON, K1A $1 \mathrm{~B} 4$ Tel: 613-957-8566, Fax: 613-946-8847, E-mail: tariq_bhatti@hc-sc.gc.ca
Like its predecessors it has become a subject of discussion, dialogue and debate, a theme for roundtables and conferences. Government structures have been or are being renamed. Policies, programs, strategies and services are being developed that are consistent with the approach.

Because the concept is so broad, we all interpret it to fit our world view and our perception of reality. This creates an interesting mosaic, a tapestry of interwoven ideas that build on and sometimes conflict with one another. The whole that would make sense of it all has yet to emerge. It may be an elusive goal to look for an ideal model, holistic, inclusive and comprehensive yet simple and elegant. Reality is too complex to be captured into a neat package. Yet we need models and frameworks. They may not explain everything but they provide useful guidance. It is in this spirit that I offer this personal reflection.

One possible way of understanding and acting on the Population Health Approach is to place it in the context of healthy human development. Both the Population Health Approach and healthy human development share concerns of collective well-being, equity, sustainability and people-centred policy and program development.

The goal of the health system is to help people enjoy a long and high-quality life. This goal is enhanced by the developmental perspective which views the life journey as one of fulfilment of potential: physical, mental, emotional, social and spiritual. Thus aging is not an affliction but rather an opportunity that opens avenues for full development. The variety and the intensity of enjoyable (and not so enjoyable) experiences are the food for nurturing our given potential. By accepting the developmental perspective as the underlying foundation for the Population Health Approach, we in the health field and in society have to be committed to providing access to the key determinants of healthy human development. The obligation is on all of us and increases with age as the intellectual, emotional, social and spiritual capital is acquired. We must reinvest this capital in future generations.

Such an approach is guided by mutual respect for fellow beings, by an obligation for community and humanity and by a responsibility for nature and reverence for all of creation. This is an ideal vision to guide our actions. Guided by such a vision, the notion of dichotomy between the individual and the collective becomes irrelevant. There is only an integrated whole.

Thus the notion of shared responsibility is grounded in a holistic vision where diversity is valued for its richness and its potential to help us all grow and develop. The respect, obligations and responsibilities for others are felt and activated from within, not operationalized from without.

As practitioners in the health field, by subscribing to a developmental perspective, we should commit to two broad areas of action. First, to increase access to the determinants of healthy human development and second, to reduce the impact of risk conditions in the environments where people live, work and play. This is our shared responsibility as collective custodians of the health system. 